\title{
Green Fabrication of Tannic Acid Inspired Magnetic Composite Nanoparticles toward Cationic Dyes Capture and Selective Degradation
}

Yihui Qian, ${ }^{\dagger}$ Shengqiu Chen, ${ }^{\dagger}$, Chao He $^{\dagger}{ }^{\dagger}$ Chen Ye, ${ }^{\S}$ Weifeng Zhao, ${ }^{\dagger}$ Shudong Sun,${ }^{\dagger}$ Yi Xie, ${ }^{*} \dagger$ and Changsheng Zhao ${ }^{*}, \dagger \|$

$\dagger$ College of Polymer Science and Engineering, State Key Laboratory of Polymer Materials Engineering, Sichuan University, Chengdu 610065, China

$¥$ Department of Mechanical Engineering, National University of Singapore, 117574, Singapore

$\S$ College of Chemistry, Sichuan University, Chengdu, 610064, China

" National Engineering Research Center for Biomaterials, Sichuan University, Chengdu 610064, China

*Corresponding author. E-mail:xieyiscu90@163.com (Y.Xie); zhaochsh70@163.com (C.S. Zhao) 


\section{Experimental Section}

\section{Materials}

Iron oxide (II,III) nanoparticles $\left(\mathrm{Fe}_{3} \mathrm{O}_{4} \mathrm{NPs}, 50-300 \mathrm{~nm}\right)$, tannin acid (TA, AR), Iron(III) chloride $\left(\mathrm{FeCl}_{3}, \mathrm{AR}, 98 \%\right)$, polyethyleneimine (PEI, $\left.\mathrm{Mw}=10,000,99 \%\right)$, titanium dioxide nanoparticles $\left(\mathrm{TiO}_{2} \mathrm{NPs}\right.$, anatase, $\left.10-25 \mathrm{~nm}, 99.8 \%\right)$ were obtained from Aladdin Reagent Co. (Shanghai, China). Methylene blue (MB, 99\%), methyl violet (MV, 99\%), rhodamine B (RhB, 99\%), methyl orange (MO, 99\%) and amaranth (AR, 99\%) were supplied by Kelong Chemical Reagent Co. Ltd. (China). All the chemicals were purchased with no further purification before use. Deionized (DI) water was used throughout the study.

\section{Preparation of the magnetic composite nanoparticles}

In this study, magnetic composite nanoparticles were fabricated based on the polyphenol-inspired polymerization. Firstly, after ultrasound-treating for more than 30 min, $\mathrm{Fe}_{3} \mathrm{O}_{4} \mathrm{NPs}(1.16 \mathrm{~g}, 5 \mathrm{mmol})$ were immersed in aqueous TA solution $\left(1.00 \mathrm{mg} \mathrm{mL}^{-1}\right.$, $90 \mathrm{~mL}$ ) for $5 \mathrm{~min}$ with shaking. Then, the nanoparticles were taken out by a magnet and transferred into aqueous $\mathrm{FeCl}_{3}$ solution $(0.50 \mathrm{mg} \mathrm{mL}-1,90 \mathrm{~mL})$, and shook for another 5 min. After that, the obtained nanoparticles were washed with DI water for several times and named as TA@ $\mathrm{Fe}_{3} \mathrm{O}_{4}$ NPs. The TA@ $\mathrm{Fe}_{3} \mathrm{O}_{4}$ NPs were then immersed into a PEI (10.00 $\mathrm{mg} \mathrm{mL}^{-1}$ ) phosphate buffer solution (PBS, $\left.\mathrm{pH}=8.5,0.01 \mathrm{mM}, 90 \mathrm{~mL}\right)$. After shaking overnight, the obtained nanoparticles were washed with DI water for several times and named as PEI-TA@ $\mathrm{Fe}_{3} \mathrm{O}_{4}$ NPs. Subsequently, the PEI-TA@ $@ \mathrm{Fe}_{3} \mathrm{O}_{4}$ NPs were put into a suspension of $\mathrm{TiO}_{2} \mathrm{NPs}(0.40 \mathrm{~g}, \mathrm{PBS}, \mathrm{pH}=8.5,90 \mathrm{~mL})$. After shaking for $12 \mathrm{~h}$, the nanoparticles were collected by a magnet. Then, the nanoparticles were washed serval times by DI water to remove the unstable $\mathrm{TiO}_{2}$. Finally, the $\mathrm{TiO}_{2}$-PEI$\mathrm{TA} @ \mathrm{Fe}_{3} \mathrm{O}_{4}$ NPs magnetic composite nanoparticles were obtained.

\section{Adsorption experiments}

To investigate the adsorption performance of the magnetic composite nanoparticles, 
batch adsorption experiments were carried out, using Methylene blue (MB) as a model organic dye. Briefly, about $50 \mathrm{mg}$ nanoparticles were applied in $10 \mathrm{~mL}$ of MB solution at room temperature. The MB concentration in the solution was determined at each predetermined time, via a UV-vis spectrophotometer (UV-1750, Shimadzu) at $664 \mathrm{~nm}$. Adsorptions of $\mathrm{MV}, \mathrm{RhB}, \mathrm{MO}$ and $\mathrm{AR}$ were studied in the same condition. The concentrations of $\mathrm{MV}, \mathrm{RhB}, \mathrm{MO}$ and $\mathrm{AR}$ in the respective adsorption solutions were determined via the UV-vis spectrophotometer at 583, 553, 465 and 520nm, respectively.

The pseudo-first-order kinetic model was widely used to analyze adsorption behavior in liquid-solid system, it could be expressed by the following equation:

$q_{A e}(m g / g)=\frac{\left(C_{A o}-C_{A e}\right) V}{M}$

$q_{A t}(m g / g)=\frac{\left(C_{A o}-C_{A t}\right) V}{M}$

$\ln \left(q_{A e}-q_{A t}\right)=\ln q_{A e}-k_{\mathrm{A} 1} t$

where $q_{A e}$ is the $\mathrm{MB}$ adsorption amount at equilibrium $(\mathrm{mg} / \mathrm{g}) ; q_{A t}$ is the MB adsorption amount at time $\mathrm{t}(\mathrm{h}) ; M(\mathrm{~g})$ and $V(\mathrm{~L})$ is the weight of $\mathrm{TiO}_{2}$-PEI-TA@ $@ \mathrm{Fe}_{3} \mathrm{O}_{4} \mathrm{NPs}$ and the volume of dyes in experiments; $k_{A 1}$ is the rate constant of pseudo-first-order adsorption.

For pseudo-second-order kinetic model, which assumed that the adsorption is a chemical process. The equation could be expressed as follows:

$\frac{t}{q_{A t}}=\frac{1}{k_{A 2} q_{A e}^{2}}+\frac{t}{q_{A e}}$

where $k_{A 2}$ is the rate constant of pseudo-second-order adsorption; the meaning of $q_{A t}$ $(\mathrm{mg} / \mathrm{g}), q_{A e}(\mathrm{mg} / \mathrm{g})$ and $t(\mathrm{~h})$ are same to those in the pseudo-first-order equation.

Langmuir and Freundlich isotherm models were used to study the equilibrium data. Langmuir isotherm model assumes that adsorption process belongs to a monolayer adsorption process. Linear form of Langmuir model equation is shown as follows:

$\frac{C_{A e}}{q_{A e}}=\frac{1}{q_{\max } \times K_{L}}+\frac{C_{A e}}{q_{\max }}$

Freundlich isotherm model usually indicates a heterogeneous adsorption process. The equation of Freundlich isotherm can be expressed as follows: 
$\ln q_{A e}=\ln K_{F}+\frac{1}{n} \ln C_{A e}$

where, $\mathrm{q}_{\mathrm{Ae}}(\mathrm{mg} / \mathrm{g})$ and $\mathrm{C}_{\mathrm{Ae}}(\mathrm{mg} / \mathrm{L})$ are the adsorption capacity and $\mathrm{MB}$ concentration at equilibrium, respectively. $\mathrm{q}_{\max }(\mathrm{mg} / \mathrm{g})$ is the theoretical maximum adsorption capacity of Langmuir isotherm model. $\mathrm{K}_{\mathrm{L}}(\mathrm{L} / \mathrm{mg})$ represents Langmuir adsorption equilibrium constant, while $\mathrm{K}_{\mathrm{F}}$ and $1 / \mathrm{n}$ are Freundlich constants which can reveal adsorption capacity of the adsorbent.

\section{Degradation experiments}

The mechanism of degradation for organic dyes by $\mathrm{TiO}_{2}$ NPs has been reported in literature ${ }^{1}$ and here is the mechanism of photocatalytic degradation for $\mathrm{MB}$ by $\mathrm{TiO}_{2}$ :

$$
\begin{aligned}
& \left(\mathrm{TiO}_{2}\right)+h v \rightarrow e_{\mathrm{CB}}^{-}+\mathrm{h}_{\mathrm{VB}}^{+} \\
& \left(\mathrm{O}_{2}\right)_{\mathrm{ads}}+e_{\mathrm{CB}}^{-} \rightarrow \mathrm{O}_{2} \cdot- \\
& \left(\mathrm{H}_{2} \mathrm{O} \Leftrightarrow \mathrm{H}^{+}+\mathrm{OH}^{-}\right)_{\mathrm{ads}}+\mathrm{h}_{\mathrm{VB}}^{+} \rightarrow \mathrm{H}^{+}+\mathrm{OH}^{\cdot} \\
& \mathrm{O}_{2} \cdot{ }^{-}+\mathrm{H}^{+} \rightarrow \mathrm{HO}_{2} \cdot \\
& 2 \mathrm{HO}_{2} \cdot \rightarrow \mathrm{H}_{2} \mathrm{O}_{2}+\mathrm{O}_{2} \\
& \mathrm{H}_{2} \mathrm{O}_{2}+e^{-} \rightarrow \mathrm{OH}^{\cdot}+\mathrm{OH}^{-} \\
& \mathrm{MB}+\mathrm{OH}^{\cdot} \rightarrow \mathrm{MB}^{\prime} \cdot+\mathrm{H}_{2} \mathrm{O} \\
& \mathrm{MB}+\mathrm{h}_{\mathrm{VB}}^{+} \rightarrow \mathrm{MB}^{+} \cdot \rightarrow \text { degradation products }
\end{aligned}
$$

The initial stage of the mechanism is $\mathrm{TiO}_{2}$ absorbing photons and being excited quickly. Next comes oxygen ionosorption, which means the initiation of the first oxygen reduction. Then, benefit from the neutralization between the $\mathrm{H}^{+}$and $\mathrm{O}^{2-}$ groups, $\mathrm{HO}_{2} \cdot$ is produced. Subsequently two radicals combine to form hydrogen peroxide and oxygen following by their decomposition which represents the occurrence of a second reduction of oxygen. In final steps, organic dyes (MB) is either attacked by hydroxyl radicals, or degraded after being trapped and oxidized by holes directly. 
To investigate the dye degradation behaviors of the magnetic composite nanoparticles, ultraviolet light (UV-light, $365 \mathrm{~nm}, 48 \mathrm{~W}$ ) was chosen to excite $\mathrm{TiO}_{2^{-}}$ PEI-TA@ $\mathrm{Fe}_{3} \mathrm{O}_{4}$ NPs for degrading dyes. The removal ratios including the dyes adsorption and degradation were calculated by using the following equation:

Removal ratio $(\%)=\frac{C_{o}-C_{t}}{C_{o}} \times 100 \%$

where $C_{o}(\mu \mathrm{mol} / \mathrm{L})$ is the solution concentration of the dyes before adsorption and degradation; $C_{t}(\mu \mathrm{mol} / \mathrm{L})$ is the concentration at a certain time $(\mathrm{t})$.

\section{Characterization of the magnetic composite nanoparticles}

Multiple techniques were carried out to characterize $\mathrm{Fe}_{3} \mathrm{O}_{4}$-TA-PEI-TiO ${ }_{2}$. Fourier transform infrared (FTIR) spectroscopy was obtained by a Nicolet 560 spectrometer (Nicolet, iS50, USA). Crystal structure analysis was carried out via an X-ray diffractometer (XRD, Rigaku, Ultima IV, Japan). X-ray photoelectron spectroscopy (XPS) was performed with an XSAM800 electron spectrometer (Kratos Analytical, U.K.). Energy dispersive spectra (EDS) was gotten by X-MAX50 energy dispersive spectrometer (Oxford, U.K.). Transmission electron microscopy (TEM, Hitachi, H700H, Japan) and scanning electron microscopy (SEM, JEOL, JMS-7500F, Japan) were used to characterize the morphology of the nanoparticles. Magnetic property was characterized using a vibrating sample magnetometer (VSM, Lakeshore-730T, USA). The zeta potentials of the composite nanoparticles' surfaces were determined by using a Zetasizer Nano-ZS (Malvern, U.K.).

\section{Results and discussion}
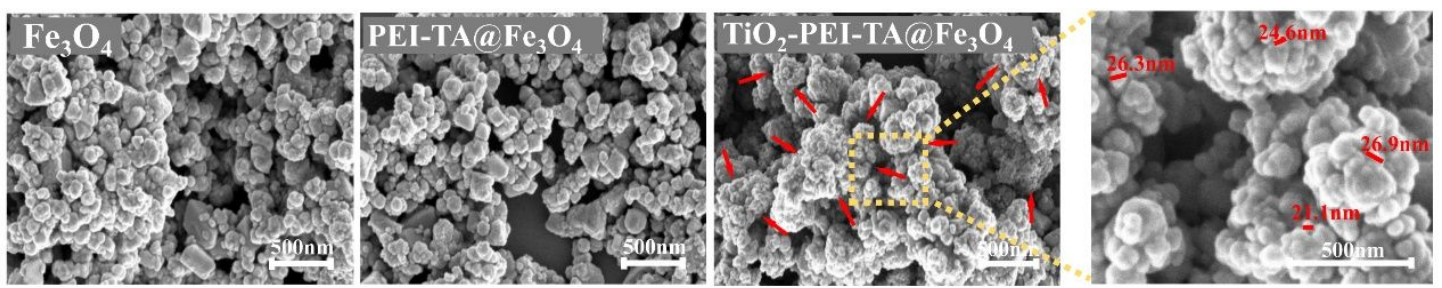

Figure S1. SEM images of $\mathrm{Fe}_{3} \mathrm{O}_{4} \mathrm{NPs}$, PEI-TA@ $@ \mathrm{Fe}_{3} \mathrm{O}_{4} \mathrm{NPs}$ and $\mathrm{TiO}_{2}$-PEI-TA $@ \mathrm{Fe}_{3} \mathrm{O}_{4}$ NPs. 
Table S1. Elemental contents determined by XPS analysis.

\begin{tabular}{|c|c|c|c|c|c|}
\hline \multirow{2}{*}{ samples } & \multicolumn{5}{|c|}{ At. conc $(\%)$} \\
\hline & Fe 2p & O 1s & C 1s & N 1s & Ti 2p \\
\hline $\mathrm{Fe}_{3} \mathrm{O}_{4}$ & 26.7 & 73.2 & 1 & 1 & l \\
\hline $\mathrm{Fe}_{3} \mathrm{O}_{4}$-TA-PEI & 13.4 & 40.8 & 40.9 & 4.9 & / \\
\hline $\mathrm{Fe}_{3} \mathrm{O}_{4}$-TA-PEI-TiO & 5.2 & 50.2 & 24.4 & 3.4 & 16.8 \\
\hline
\end{tabular}

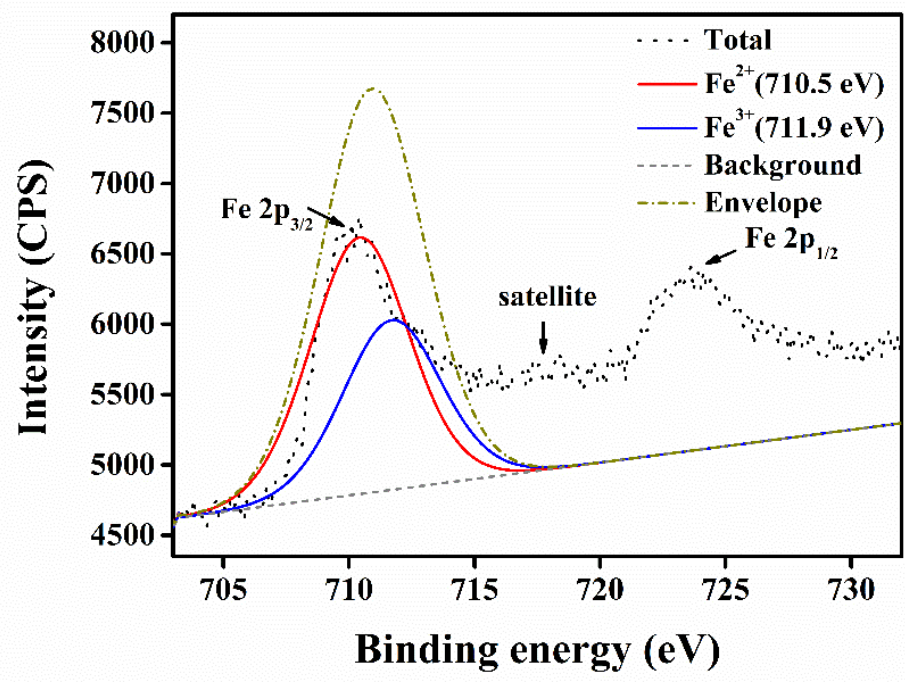

Figure S2. Fe 2p XPS spectra of $\mathrm{TiO}_{2}$-PEI-TA@ $\mathrm{Fe}_{3} \mathrm{O}_{4} \mathrm{NPs}$

a

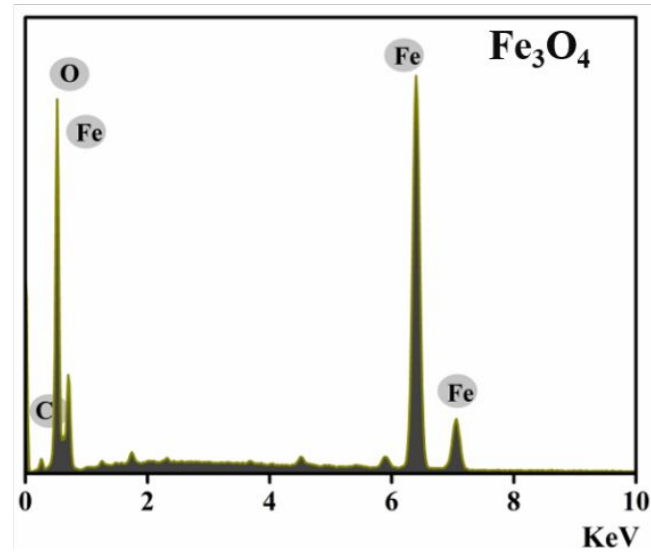

b

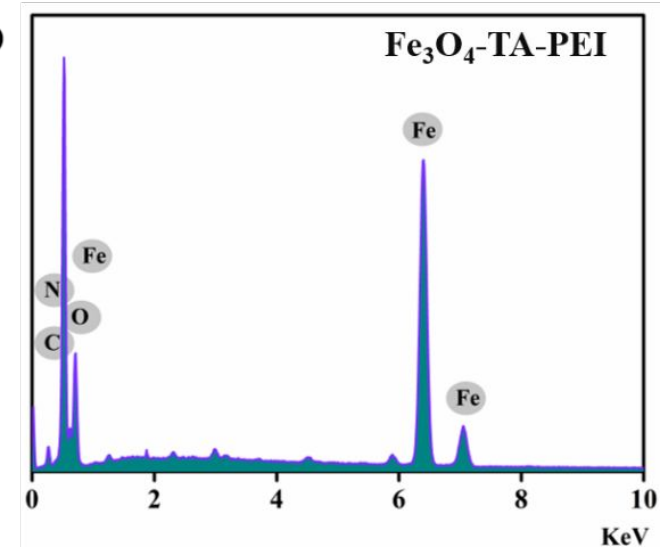

Figure S3. (a) EDS spectra of $\mathrm{Fe}_{3} \mathrm{O}_{4}$; (b) EDS spectra of PEI-TA@ $\mathrm{Fe}_{3} \mathrm{O}_{4}$ NPs. 

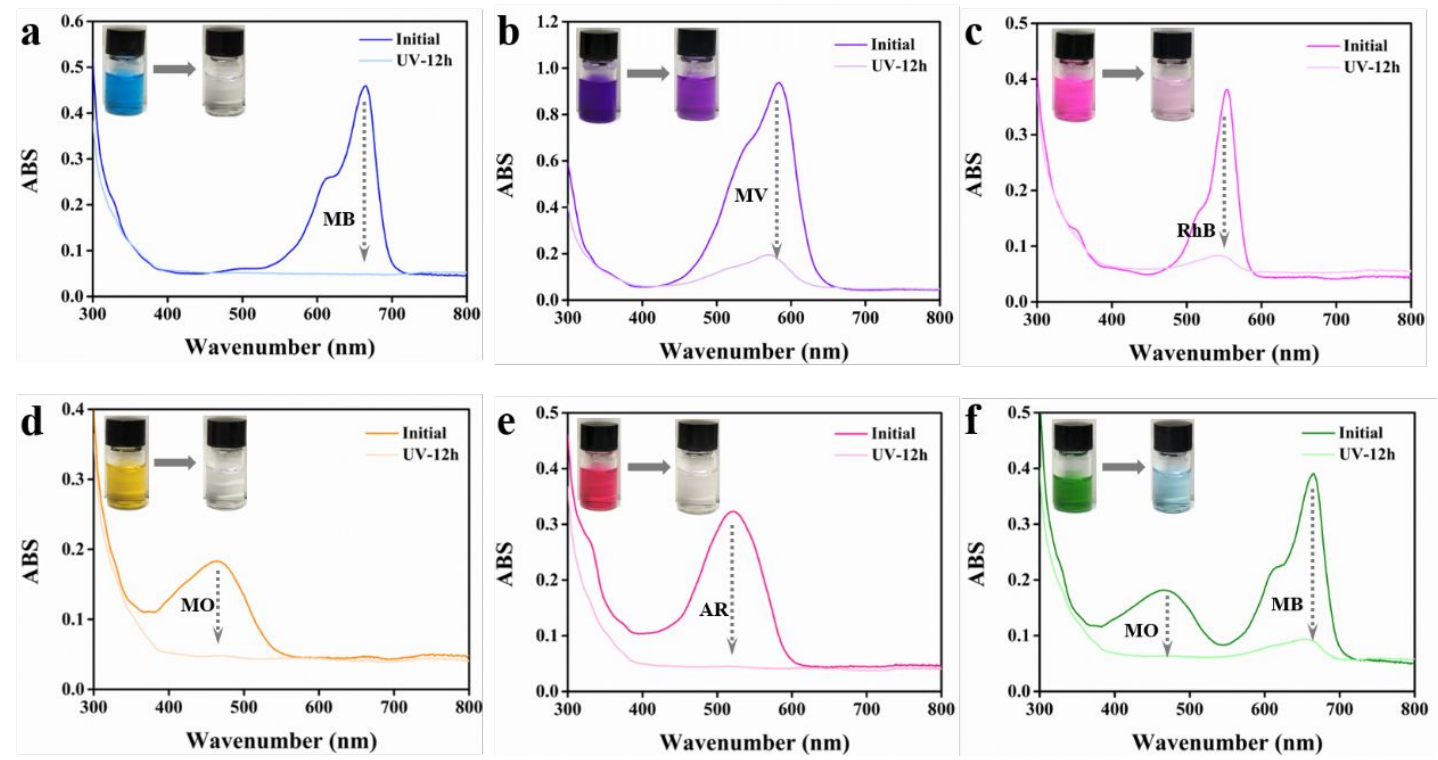

Figure S4. (a-e) The degradation of $\mathrm{MB}, \mathrm{MV}, \mathrm{RhB}, \mathrm{MO}, \mathrm{AR}$ by $\mathrm{TiO}_{2} \mathrm{NPs}$; (f) the degradation for the mixture of MO and MB by the pure $\mathrm{TiO}_{2} \mathrm{NPs}$.

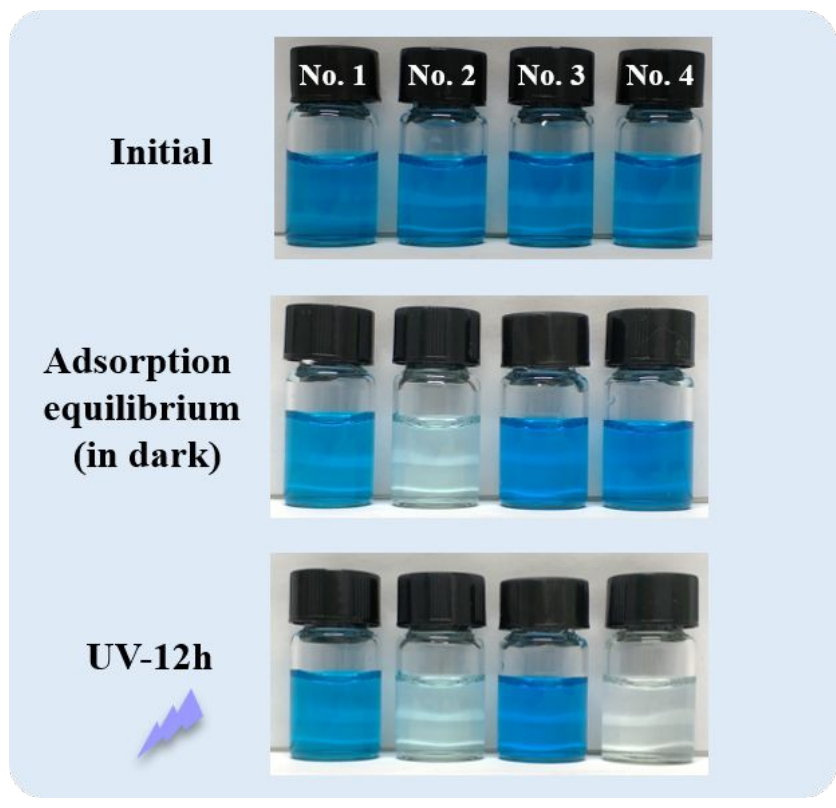

Figure S5. Photographs of treated MB solutions at different reaction stages, No.1-4 correspond to $\mathrm{Fe}_{3} \mathrm{O}_{4}, \mathrm{TA} @ \mathrm{Fe}_{3} \mathrm{O}_{4}, \mathrm{PEI}-\mathrm{TA} @ \mathrm{Fe}_{3} \mathrm{O}_{4}$ and $\mathrm{TiO}_{2}-\mathrm{PEI}-\mathrm{TA} @ \mathrm{Fe}_{3} \mathrm{O}_{4}$ NPs, respectively.

Table S2. Elemental contents of different $\mathrm{TiO}_{2}-\mathrm{PEI}-\mathrm{TA} @ \mathrm{Fe}_{3} \mathrm{O}_{4} \mathrm{NPs}$ determined by EDS analysis. 


\begin{tabular}{cccccc}
\hline \multirow{2}{*}{ samples } & \multicolumn{5}{c}{ content (\%) } \\
\cline { 2 - 6 } & $\mathbf{F e}$ & $\mathbf{O}$ & $\mathbf{C}$ & $\mathbf{N}$ & $\mathbf{T i}$ \\
\hline $\mathbf{5 : 1}$ & 41.8 & 47.0 & 8.2 & 1.2 & 1.8 \\
$\mathbf{3 : 1}$ & 32.7 & 53.8 & 8.5 & 0.7 & 4.3 \\
$\mathbf{1 : 1}$ & 18.3 & 60.9 & 13.8 & 0.4 & 6.6 \\
$\mathbf{1 : 3}$ & 13.0 & 59.0 & 7.2 & 0.1 & 20.7 \\
\hline
\end{tabular}
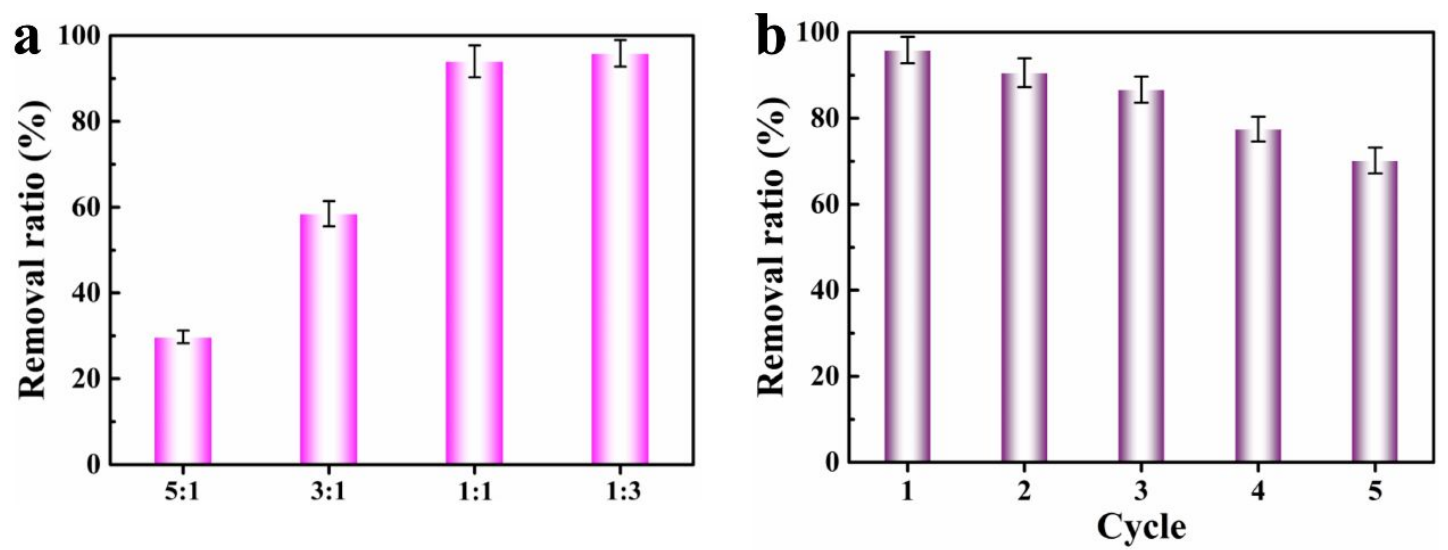

Figure S6. (a) The removal ratios to $\mathrm{MB}$ by $\mathrm{TiO}_{2}-\mathrm{PEI}-\mathrm{TA} @ \mathrm{Fe}_{3} \mathrm{O}_{4} \mathrm{NPs}$ at different molar ratio $\left(\mathrm{Fe}_{3} \mathrm{O}_{4}: \mathrm{TiO}_{2}\right)$; (b) the removal ratios by $\mathrm{TiO}_{2}$-PEI-TA@ $\mathrm{Fe}_{3} \mathrm{O}_{4}(5: 1)$ of five cycles toward MB (the initial concentrations of MB solutions both are $50 \mu \mathrm{mol} / \mathrm{L}$ ).

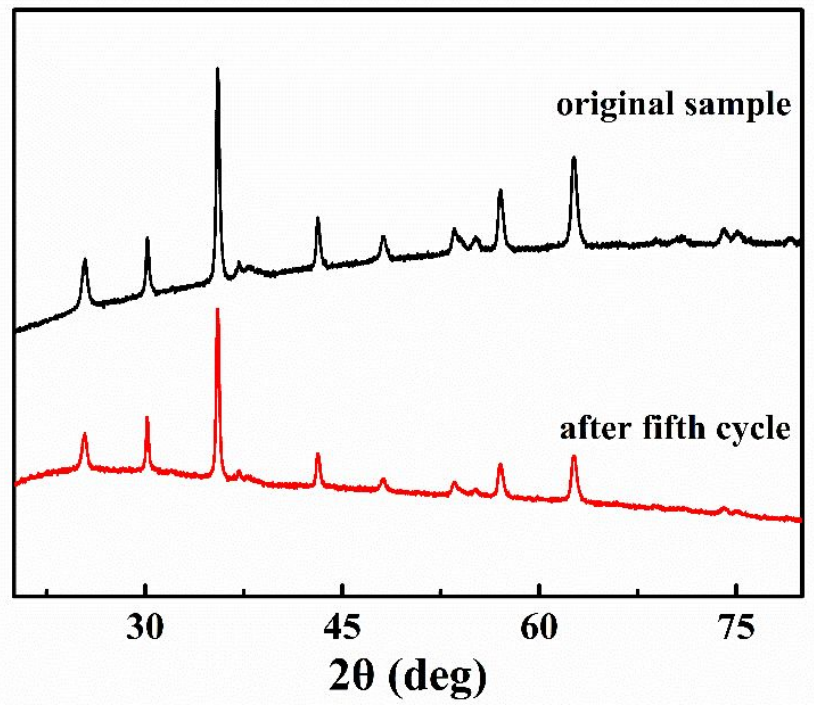

Figure S7. Powder XRD pattern of original $\mathrm{TiO}_{2}$-PEI-TA $@ \mathrm{Fe}_{3} \mathrm{O}_{4} \mathrm{NPs}$ and that obtained after five adsorption-degradation cycles. 
Table S3. The raw material price list.

\begin{tabular}{|c|c|c|}
\hline Materials & Reagent supplier & Price \\
\hline $\mathrm{Fe}_{3} \mathrm{O}_{4} \mathrm{NPs}$, 50-300 nm & Aladdin Reagent Co. (Shanghai, China) & $¥ 249.00 / 250 \mathrm{~g}$ \\
\hline $\mathrm{TiO}_{2} \mathrm{NPs}, 10-25 \mathrm{~nm}$ & Aladdin Reagent Co. (Shanghai, China) & $¥ 298.00 / 500 \mathrm{~g}$ \\
\hline Tannic Acid (TA) & Aladdin Reagent Co. (Shanghai, China) & $¥ 229.00 / 250 \mathrm{~g}$ \\
\hline PEI, Mw $=10,000$ & Aladdin Reagent Co. (Shanghai, China) & $¥ 316.00 / 100 \mathrm{~g}$ \\
\hline
\end{tabular}

\section{Reference}

(1) Houas, A.; Lachheb, H.; Ksibi, M.; Elaloui, E.; Guillard, C.; Herrmann, J.-M. Photocatalytic degradation pathway of methylene blue in water. Appl. Catal. BEnviron. 2001, 31, 145-157. 